\title{
FPGA-Based Model-Free Nonlinear Control Approach with Application to First Order Delays System
}

\author{
Iman Nazari ${ }^{1}$, Farzin Piltan ${ }^{1}$, Ali Roshanzamir ${ }^{1,2}$, Arman Jahed ${ }^{1}$, Saman \\ Namvarrechi ${ }^{1}$ and Nasri B. Sulaiman ${ }^{1,3}$ \\ ${ }^{1}$ Intelligent Systems and Robotics Lab, Iranian Institute of Advanced Science and \\ Technology (IRAN SSP), Shiraz/Iran \\ ${ }^{2}$ Department Division of Electronic Engineering, Faculty of Engineering, \\ Hanyang University, Korea \\ ${ }^{3}$ Department of Electrical and Electronic Engineering, Faculty of Engineering, \\ University Putra Malaysia, Malaysia \\ piltan_f@iranssp.org,WWW.IRANSSP.ORG/english
}

\begin{abstract}
The Proportional-Integral-Derivative (PID) controller to control of first order delay system has fluctuations in presence of uncertainty. To reduce the rate of fluctuations as well as improve the first order delay rise time, the first objective is design a ProportionalIntegral-Integral-Derivative $\left(P I^{2} D\right)$ controller. This algorithm is complex control technique which requires faster micro-controllers; therefore the second objective of this article is to present the implementation of the $\mathrm{PI}^{2} \mathrm{D}$ on the Field Programmable Gate Array (FPGA). The maximum output required time in $P I^{2} D$ is $32.88 \mathrm{~ns}$ and the maximum output frequency in $\mathrm{PI}^{2} \mathrm{D}$ algorithm is $30.4 \mathrm{MHZ}$.
\end{abstract}

Keywords: First order delays system, PID controller, PI ${ }^{2} D$ algorithm, FPGA control algorithm

\section{First Order Delay System}

First order delay (FOD) is a nonlinear and time variant system. A first order model can represent many industrial processes; Equation (1) shows the mathematical plant model (in $s$-plane). Discrete transfer function of this model has obtained using $\mathrm{ZOH}$ method, and the selected sampling period (T) is 0.1, Equation (2) shows the discrete transfer functions, (in $z$-plane).

$$
C S_{1}(s)=\frac{1}{S+1}
$$

and;

$$
C S_{1}(z)=\frac{0.09516}{Z-0.9048}, T=0.1
$$

The time delay occurs when a sensor or an actuator are used with a physical separation. Equation (3), shows the mathematical plant model (in s-plane). Discrete transfer functions of this model has been obtained using $\mathrm{ZOH}$ method, and the selected sampling period ( $\mathrm{T}$ ) is 0.1, Equation (4 and 5), show the discrete transfer functions, (in z-plane).

$$
\begin{aligned}
& C S_{2}(s)=\frac{1}{S^{2} \times(S+1)} \\
& C S_{2}(z)=Z^{-2} \times C S_{1}(z)
\end{aligned}
$$




$$
\mathrm{CS}_{2}(\mathrm{z})=Z^{-2} \times \frac{0.09516}{Z-0.9048}, T=0.1
$$

\section{MATLAB-Based Controller}

Design PID and $\mathrm{PI}^{2} \mathrm{D}$ MATLAB-based controller introduce in this part. The formulation of PID controller is:

$$
U_{P I D}=K_{p} \times e+K_{v}\left(\frac{d e}{d t}\right)+K_{i} \int e d t=K_{p} \times e+K_{v} \dot{e}+K_{i} \sum e
$$

Where $\boldsymbol{e}=\boldsymbol{q}_{i_{d}}-\boldsymbol{q}_{i_{a}}, \dot{e}=\dot{\boldsymbol{q}}_{i_{d}}-\dot{\boldsymbol{q}}_{i_{a}}$ and $\sum \boldsymbol{e}=\int\left(\boldsymbol{q}_{i_{d}}-\boldsymbol{q}_{i_{a}}\right)$.

To show this controller is stable and achieves zero steady state error, the Lyapunov function is introduced;

$$
\begin{aligned}
& V=\frac{1}{2}\left[\dot{q}^{T} S \dot{q}+e^{T} K_{p} e\right]= \\
& \frac{1}{2} \frac{d}{d t}\left[\dot{q}^{T} S \dot{q}\right]=\dot{q} U
\end{aligned}
$$

If the conversation energy is written by the following form:

$$
\frac{1}{2} \frac{d}{d t}\left[\dot{q}^{T} S \dot{q}\right]=\dot{q} U
$$

Where $(\dot{\boldsymbol{q}} \boldsymbol{U})$ shows the power inputs and $\frac{1}{2} \frac{d}{d t}\left[\tilde{\boldsymbol{q}}^{T} \boldsymbol{S} \dot{\boldsymbol{q}}\right]$ is the derivative of the kinetic energy.

$$
\dot{V}=\dot{q}^{T}\left[U+K_{p} e\right]
$$

Based on $\boldsymbol{U}=-\boldsymbol{K}_{p_{i}} \boldsymbol{e}-\boldsymbol{K}_{v_{i}} \dot{e}$, we can write:

$$
\dot{V}=\dot{q}^{T} K_{p} \dot{q} \leq 0
$$

If $\dot{V}=\mathbf{0}$, we have

$$
\dot{q}=0 \rightarrow \ddot{q}=0 \rightarrow \ddot{q}=A^{-1} K_{p} e \rightarrow e=0
$$

In this state, the actual trajectories converge to the desired state.

However, PID controller is used in many applications but it has the challenge in presence of uncertainty. To reduce these challenges $\mathrm{PI}^{2} \mathrm{D}$ controller is introduced.

$U_{P I^{2} D}=K_{p} \times e+K_{v}\left(\frac{d e}{d t}\right)+\left[K_{i_{1}} \int e d t \times K_{i_{2}} \int e d t\right]=K_{p} \times e+K_{v} \dot{e}+K_{i_{1}} \times$ $K_{i_{2}}\left(\sum e\right)^{2}$

$U_{P I^{2} D}=K_{p}+K_{v} S+\frac{K_{\hat{I}_{1}} \times K_{\tilde{I}_{2}}}{s^{2}}$

Lyapunov function is introduced;

$$
\begin{aligned}
& V=\frac{1}{2}\left[\dot{q}^{T} S \dot{q}+e^{T} K_{p} e+\frac{K_{i_{1}} \times K_{i_{2}}}{S^{2}} e^{T}\right]= \\
& \frac{1}{2} \frac{d}{d t}\left[\dot{q}^{T} S \dot{q}\right]+\frac{1}{2} \frac{K_{i_{1}} \times K_{i_{2}}}{S^{2}}=\dot{q} U+\sum U \\
& \dot{V}=\dot{q}^{T}\left[U+K_{p} e+K_{i_{1}} \times K_{i_{2}} \sum U\right]
\end{aligned}
$$


If $\dot{V}=0$

$$
\dot{q}=0 \rightarrow \ddot{q}=0 \rightarrow \ddot{q}=K_{p} e+K_{i_{1}} \times K_{i_{2}} \dot{e} \rightarrow e=0 \text { or } \ddot{e}=0
$$

Figure 1, shows the trajectory following in PID controller, PI2D controller, and control free in first order delay system. Regarding the following graph, the rise time in control free first order delay system in a certain condition is about 3.939 seconds and, the rise time in PID control algorithm is about 0.36 seconds and $\mathrm{PI}^{2} \mathrm{D}$ controller reduces the rise time to 0.023 seconds.

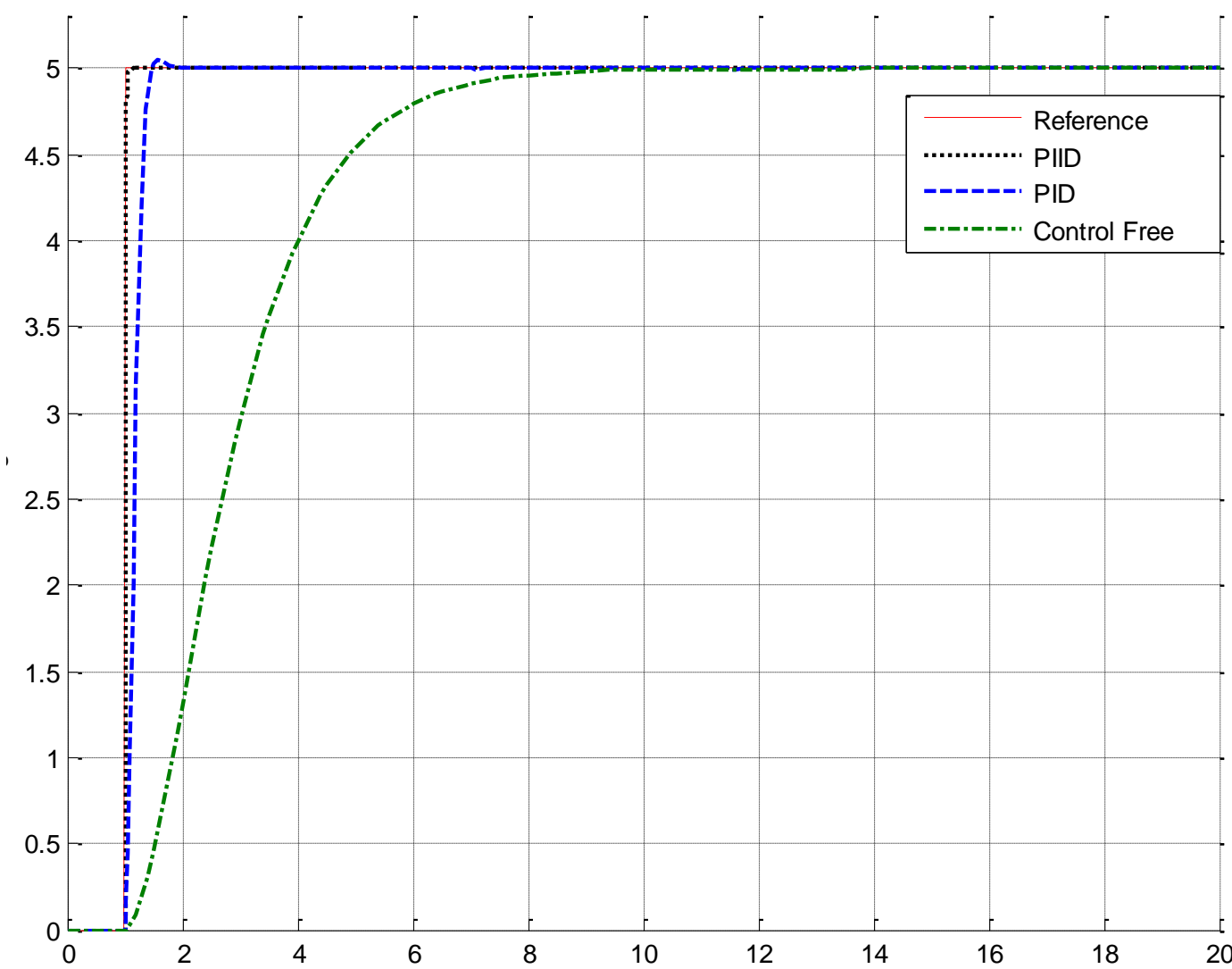

Figure 1. Trajectory Following: $\mathrm{PID}$ Controller, $\mathrm{PI}^{2} \mathrm{D}$ and Control Free

Figure 2, shows the power of disturbance rejection in PID controller, $\mathrm{PI}^{2} \mathrm{D}$ controller, and control free for first order delay system. In presence of uncertainty, $\mathrm{PI}^{2} \mathrm{D}$ controller is robust than PID controller and control free technique. Based on the following graph, the rate of overshoot in PID controller has increased from 5\% in a certain condition to 50\% in uncertain condition. The rate of overshoot in $\mathrm{PI}^{2} \mathrm{D}$ increased as well as PID controller from $0 \%$ in the certain condition to $7 \%$ in presence of uncertainty. The second parameters to the comparison between PID and $\mathrm{PI}^{2} \mathrm{D}$ algorithm are rise time. The rate of rise-time in PID controller has increased from 0.36 second to 1.3 seconds in presence of uncertainty. However, the activation time in PID controller has been changed but $\mathrm{PI}^{2} \mathrm{D}$ controller has the steady stable in this factor. 


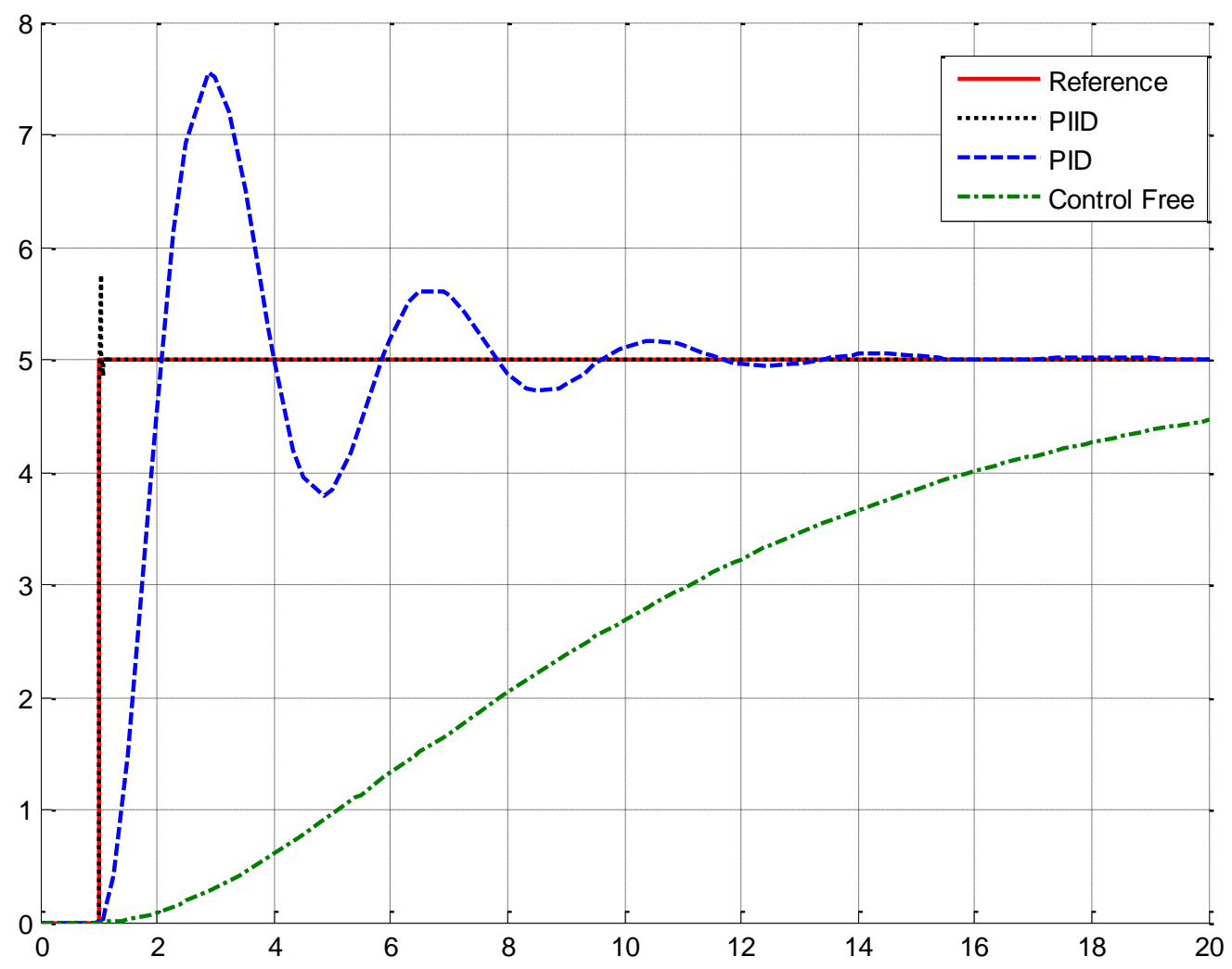

Figure 2. Disturbance Rejection: PID Controller, $\mathrm{PI}^{2} \mathrm{D}$ and Control Free

\section{FPGA-Based Algorithm}

The following formulation shows the derivative algorithm [1-2]:

$d(e)=\frac{\operatorname{Din}(t)-\operatorname{Din}(t-1)}{\Delta t}=(\operatorname{Din}(k+1)-\operatorname{Din}(k)) \times$ sample time

$\operatorname{Din}=q_{d}-q_{a}$

However $\boldsymbol{q}_{d}$ and $\boldsymbol{q}_{\boldsymbol{a}}$ are 30 bits but Din is 40 bits. In derivative algorithm, delay time is the main challenge. In this research the value of sample time is"01010". To design $\operatorname{Din}(\boldsymbol{k}+\mathbf{1})$, design a register has the main role. The vast majority of modern commercial systems are built with registers using positive edge-triggered D flip-flops. The following formulation shows the derivative algorithm [1-3]:

$I(\text { out })_{(K)}=I(\text { out })_{(k-1)}+($ Ki $\times e(k) \times$ sample time $)$

The $\mathrm{Z}$ formulation of PID controller is design as follows [4-5]:

$U[k]=U[k-1]+K_{1} \times e[k]+K_{2} \times e[k-1]+K_{3} \times e[k-2]$

Figure 3, shows the HDL synthesize report for PID algorithm. 


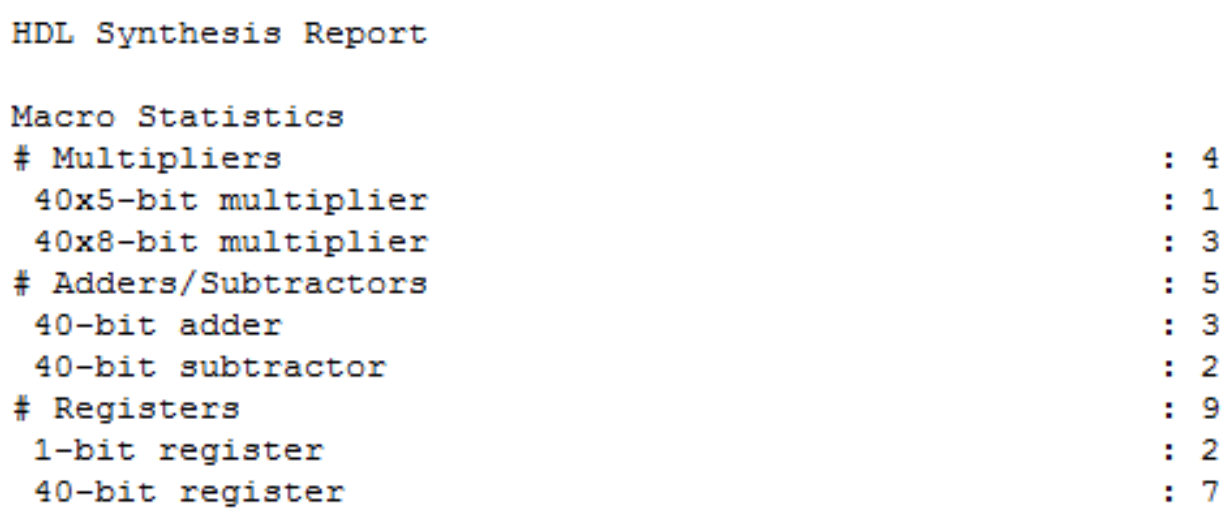

Figure 3. HDL Synthesis Report: PID Algorithm

Figure 4, shows advanced HDL synthesis report in PID algorithm.

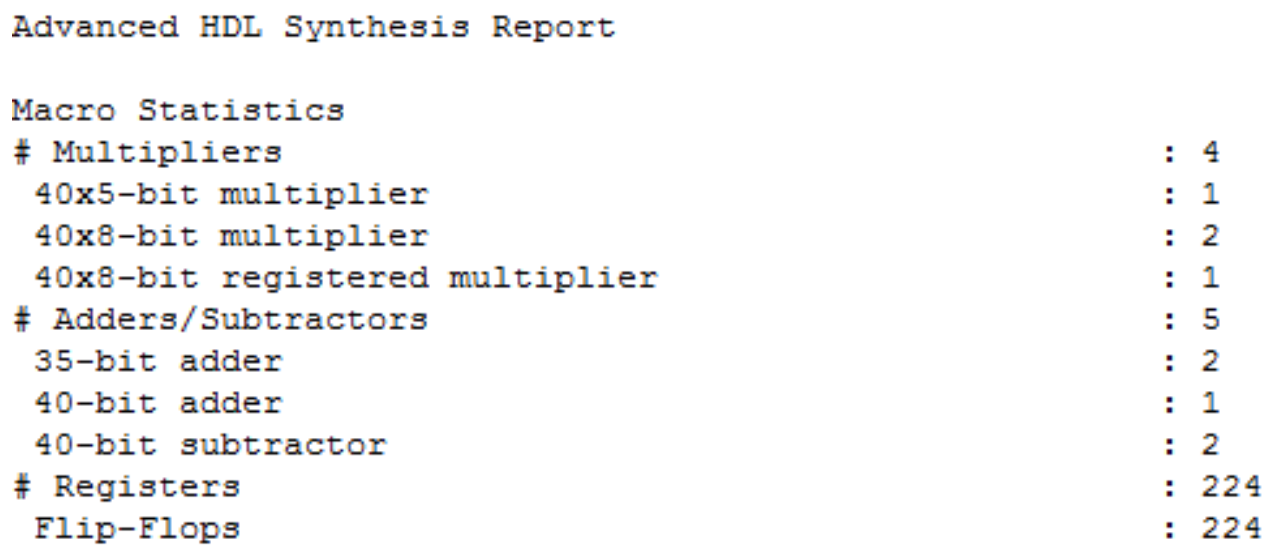

Figure 4. Advanced HDL Synthesis Report: PID Algorithm

Figure 5, shows the device utilization summary in PID algorithm.

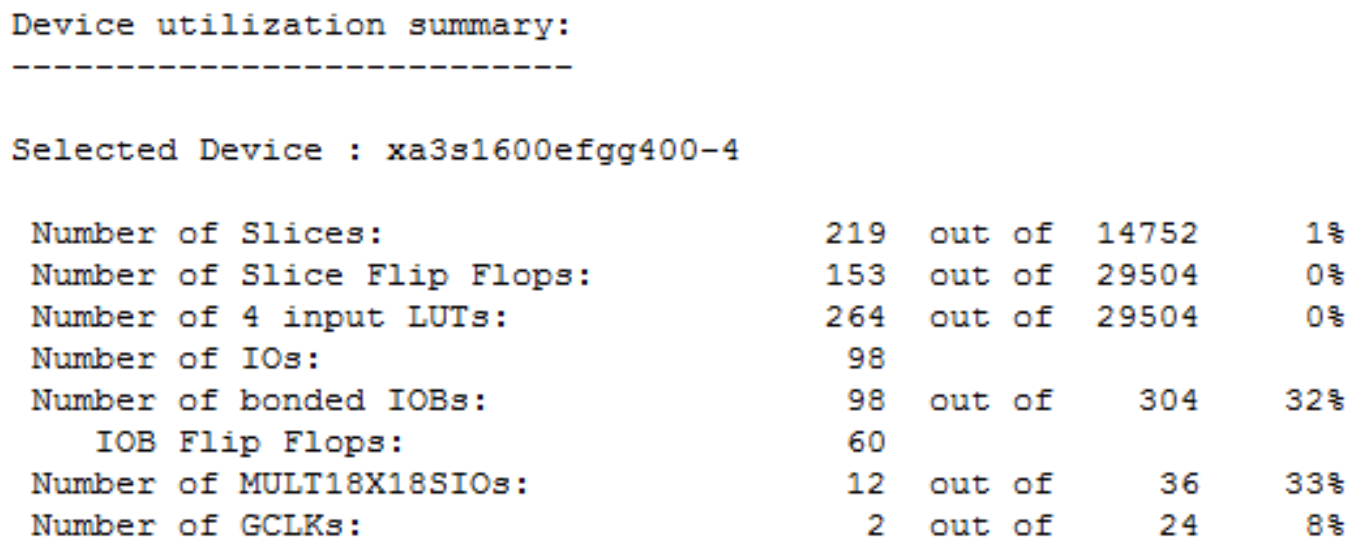

Figure 5. Device Utilization Summary: PID Algorithm

Figure 6, shows the timing summary in PID algorithm. 


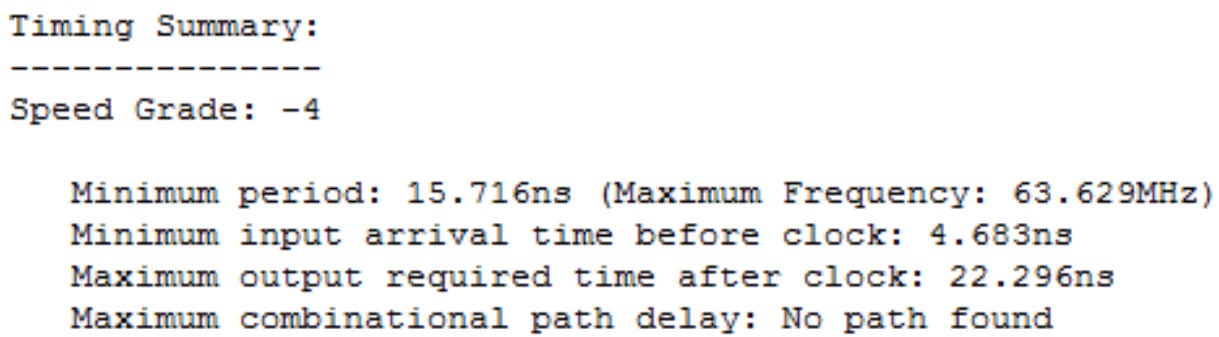

Figure 6. Timing Summary: PID Algorithm

Regarding to Figure 6, the Maximum frequency in this design is $44.85 \mathrm{MHz}$. however the rate of clock is $63.629 \mathrm{MHz}$ but in PID algorithm the maximum frequency is $44.85 \mathrm{MHz}$.

The FPGA-based $\mathrm{PI}^{2} \mathrm{D}$ formulation is:

$U[k]=U[k-1]+K_{1} \times e[k]+K_{2} \times e[k-1]+K_{3} \times e[k-2] \times e[k-3]$

Figure 7, shows the HDL synthesize report for $\mathrm{PI}^{2} \mathrm{D}$ algorithm.

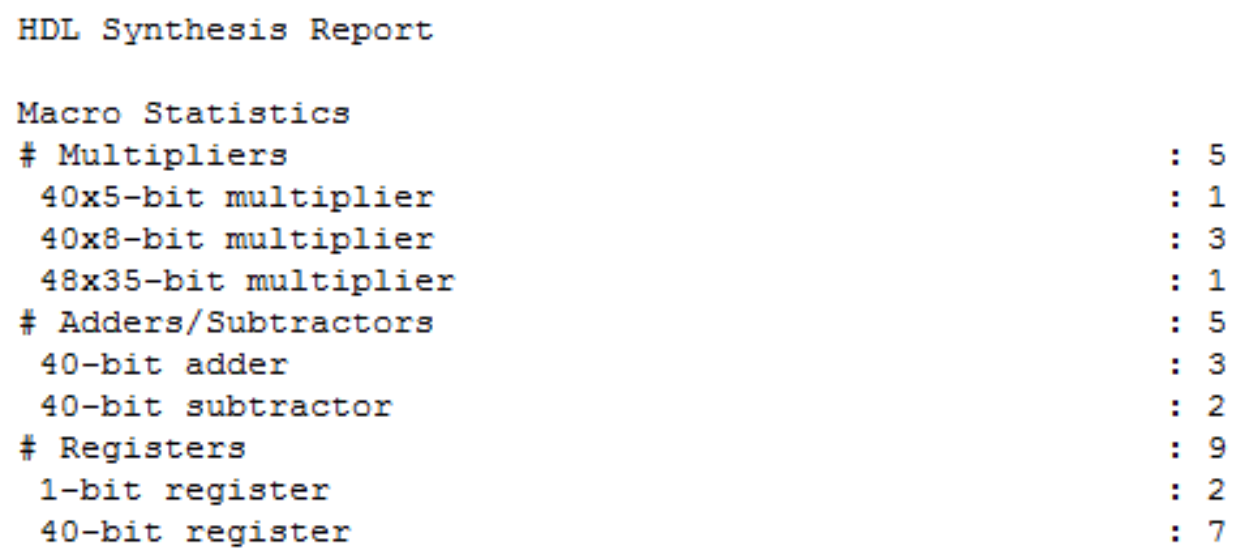

Figure 7. HDL Synthesis Report: $\mathrm{PI}^{2} \mathrm{D}$ Algorithm

Figure 8, shows advanced HDL synthesis report in $\mathrm{PI}^{2} \mathrm{D}$ algorithm.

$\begin{array}{ll}\text { Advanced HDL Synthesis Report } & \\ & \\ \text { Macro Statistics } & : 5 \\ \text { \# Multipliers } & : 1 \\ \text { 40x5-bit multiplier } & : 2 \\ \text { 40x8-bit multiplier } & : 1 \\ \text { 40x8-bit registered multiplier } & : 1 \\ \text { 48x35-bit multiplier } & : 5 \\ \text { \# Adders/Subtractors } & : 2 \\ \text { 35-bit adder } & : 1 \\ \text { 40-bit adder } & : 2 \\ \text { 40-bit subtractor } & : 224 \\ \text { \# Registers } & : 224 \\ \text { Flip-Flops } & \end{array}$

Figure 8. Advanced HDL Synthesis Report: $\mathrm{PI}^{2} \mathrm{D}$ Algorithm

Figure 9, shows the device utilization summary in $\mathrm{PI}^{2} \mathrm{D}$ algorithm. 


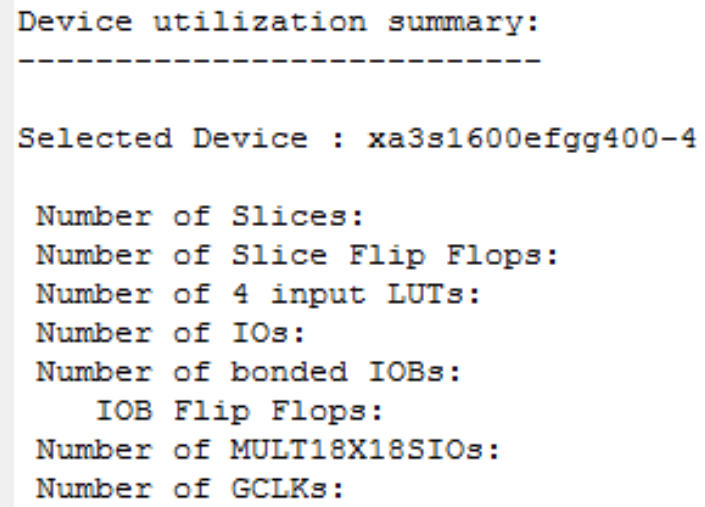

$\begin{array}{rrrr}264 & \text { out of } & 14752 & 1 \% \\ 153 & \text { out of } & 29504 & 0 \% \\ 350 & \text { out of } & 29504 & 1 \% \\ 140 & & & \\ 140 & \text { out of } & 304 & 46 \% \\ 60 & & & \\ 17 & \text { out of } & 36 & 47 \% \\ 2 & \text { out of } & 24 & 8 \%\end{array}$

Figure 9. Device Utilization Summary: $\mathrm{PI}^{2} \mathrm{D}$ Algorithm

According to Figure 9, and compared with Figure 5; the numbers of slices are increases from 219 in PID technique to 264 in PI $^{2} \mathrm{D}$. The numbers of LUTs are increases from 264 in PID technique to 350 in $\mathrm{PI}^{2} \mathrm{D}$. The numbers of IOs are increases from 98 in PID technique to 140 in $\mathrm{PI}^{2} \mathrm{D}$. The rates of bounded IOs are increase from $32 \%$ in PID to $46 \%$ in $\mathrm{PI}^{2} \mathrm{D}$. The rates of multipliers are increase from $33 \%$ in $\mathrm{PID}$ to $47 \%$ in $\mathrm{PI}^{2} \mathrm{D}$.

Figure 10, shows the timing summary in $\mathrm{PI}^{2} \mathrm{D}$ algorithm.

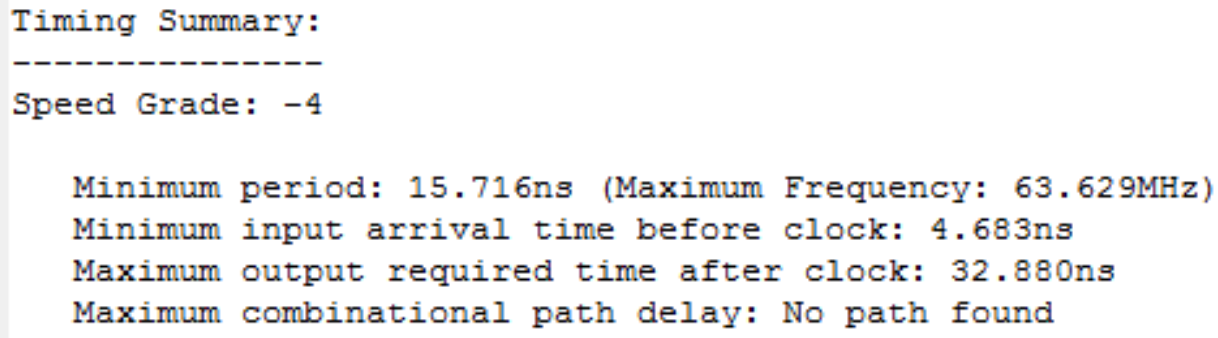

Figure 10. Timing Summary: $\mathrm{PI}^{2} \mathrm{D}$ Algorithm

Regarding to Figure 10, the Maximum frequency in this design is $\mathbf{3 0 . 4} \mathbf{~ M H z}$. However the rate of clock is $63.629 \mathrm{MHz}$ but in $\mathrm{PI}^{2} \mathrm{D}$ algorithm the maximum frequency is $30.4 \mathrm{MHz}$. According to comparison between $\mathrm{PID}$ and $\mathrm{PI}^{2} \mathrm{D}$, the maximum output required time in PID is $22.29 \mathrm{~ns}$ but in $\mathrm{PI}^{2} \mathrm{D}$ is $32.88 \mathrm{~ns}$ and the maximum output frequency in PID controller is $44.85 \mathrm{MHZ}$ but in $\mathrm{PI}^{2} \mathrm{D}$ algorithm is $30.4 \mathrm{MHZ}$.

\section{Conclusion}

In this paper, FPGA-based $\mathrm{PI}^{2} \mathrm{D}$ (nonlinear) controller for delay system is design and analysis. In rise time point of view, the rise time in $\mathrm{PI}^{2} \mathrm{D}$ is better than PID algorithm in certain as well as uncertain condition. In robustness and stability point of view, $\mathrm{PI}^{2} \mathrm{D}$ is more stable than PID algorithm (Figure 2). In uncertain condition PID controller has oscillation which caused to instability in delay system. According to comparison between FPGA-based PID and FPGA-based PI $^{2} \mathrm{D}$ controllers, the maximum output required time in PID is $22.29 \mathrm{~ns}$ but in $\mathrm{PI}^{2} \mathrm{D}$ is $32.88 \mathrm{~ns}$ and the maximum output frequency in PID controller is $44.85 \mathrm{MHZ}$ but in $\mathrm{PI}^{2} \mathrm{D}$ algorithm is $30.4 \mathrm{MHZ}$. 


\section{Acknowledgement}

The authors would like to thank the anonymous reviewers for their careful reading of this paper and for their helpful comments. This work was supported by the Iranian Institute of Advance Science and Technology Program of Iran under grant no. 2015Persian Gulf-1.

Iranian center of Advance Science and Technology (IRAN SSP) is one of the independent research centers specializing in research and training across of Control and Automation, Electrical and Electronic Engineering, and Mechatronics \& Robotics in Iran. At IRAN SSP research center, we are united and energized by one mission to discover and develop innovative engineering methodology that solve the most important challenges in field of advance science and technology. The IRAN SSP Center is instead to fill a long standing void in applied engineering by linking the training a development function one side and policy research on the other. This center divided into two main units:

- $\quad$ Education unit

- $\quad$ Research and Development unit

\section{References}

[1] R. Faraji, A. Rouholamini, H. R. Naji, R. Fadaeinedjad and M. R. Chavoshian, "FPGA-based real time incremental conductance maximum power point tracking controller for photovoltaic systems", Power Electronics, IET, vol. 7, no. 5, (2014), pp. 1294-1304.

[2] S. Ghosh, R. K. Barai, S. Bhattarcharya, P. Bhattacharyya, S. Rudra, A. Dutta and R. Pyne, "An FPGA based implementation of a flexible digital PID controller for a motion control system", In Computer Communication and Informatics (ICCCI), 2013 International Conference on, IEEE., (2013) January, pp. 1-6.

[3] K. Lochan and B. K. Roy, "Control of Two-link 2-DOF Robot Manipulator Using Fuzzy Logic Techniques: A Review", In Proceedings of Fourth International Conference on Soft Computing for Problem Solving, Springer India, (2015), pp. 499-511.

[4] J. Li, L. Liu, Y. Wang and W. Liang, "Adaptive hybrid impedance control of robot manipulators with robustness against environment's uncertainties", In Mechatronics and Automation (ICMA), 2015 IEEE International Conference on, IEEE, (2015), August, pp. 1846-1851.

[5] Y. Q. Bao and Y. Li, "FPGA-based design of grid friendly appliance controller", Smart Grid, IEEE Transactions on, vol. 5, no. 2, (2014), pp. 924-931.

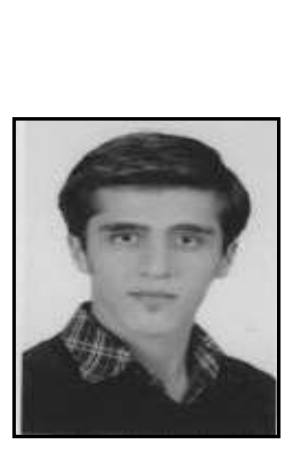

\section{Authors}

Iman nazari, $\mathrm{He}$ is currently Research Assistant at Institute of Advanced Science and Technology, Research and Training Center, IRAN SSP. He is research assistant of team (8 researchers) to design a Micro-electronic Based nonlinear controller for first order delay system since March, 2015, research student (45 researchers) to Nonlinear control of Industrial Robot Manipulator for Experimental Research and Education from October 2010 to October 2011, and published 7 journal papers since 2011 to date. His current research interests are nonlinear control, artificial control system, Microelectronic Device, and HDL design

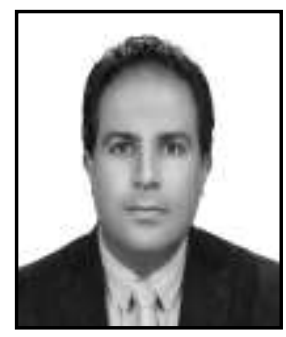

Farzin Piltan, $\mathrm{He}$ is an outstanding scientist in the field of Electronics and Control engineering with expertise in the areas of nonlinear systems, robotics, and microelectronic control. Mr. Piltan is an advanced degree holder in his field. Currently, Mr. Piltan is the Head of Mechatronics, Intelligent System, and Robotics Laboratory at the Iranian Institute of Advanced Science and Technology (IRAN SSP). Mr. Piltan led several high impact projects involving more than 
150 researchers from countries around the world including Iran, Finland, Italy, Germany, South Korea, Australia, and the United States. Mr. Piltan has authored or co-authored more than 140 papers in academic journals, conference papers and book chapters. His papers have been cited at least 3900 times by independent and dependent researchers from around the world including Iran, Algeria, Pakistan, India, China, Malaysia, Egypt, Columbia, Canada, United Kingdom, Turkey, Taiwan, Japan, South Korea, Italy, France, Thailand, Brazil and more. Moreover, Mr. Piltan has peer-reviewed at least 23 manuscripts for respected international journals in his field. Mr. Piltan will also serve as a technical committee member of the upcoming EECSI 2015 Conference in Indonesia. Mr. Piltan has served as an editorial board member or journal reviewer of several international journals in his field as follows: International Journal of Control And Automation (IJCA), Australia, ISSN: 2005-4297, International Journal of Intelligent System and Applications (IJISA), Hong Kong, ISSN:2074-9058, IAES International Journal Of Robotics And Automation, Malaysia, ISSN:2089-4856, International Journal of Reconfigurable and Embedded Systems, Malaysia, ISSN:2089-4864. Mr. Piltan has acquired a formidable repertoire of knowledge and skills and established himself as one of the leading young scientists in his field. Specifically, he has accrued expertise in the design and implementation of intelligent controls in nonlinear systems. Mr. Piltan has employed his remarkable expertise in these areas to make outstanding contributions as detailed follows:Nonlinear control for industrial robot manipulator (2010-IRAN SSP), Intelligent Tuning The Rate Of Fuel Ratio In Internal Combustion Engine (2011-IRANSSP), Design High Precision and Fast Dynamic Controller For Multi-Degrees Of Freedom Actuator (2013IRANSSP), Research on Full Digital Control for Nonlinear Systems (2011-IRANSSP), Micro-Electronic Based Intelligent Nonlinear Controller (2015-IRANSSP), Active Robot Controller for Dental Automation (2015-IRANSSP), Design a Micro-Electronic Based Nonlinear Controller for First Order Delay System (2015-IRANSSP). The above original accomplishments clearly demonstrate that $\mathrm{Mr}$. Piltan has performed original research and that he has gained a distinguished reputation as an outstanding scientist in the field of electronics and control engineering. Mr. Piltan has a tremendous and unique set of skills, knowledge and background for his current and future work. He possesses a rare combination of academic knowledge and practical skills that are highly valuable for his work. In 2011, he published 28 first author papers, which constitute about 30\% of papers published by the Department of Electrical and Electronic Engineering at University Putra Malaysia. Additionally, his 28 papers represent about $6.25 \%$ and $4.13 \%$ of all control and system papers published in Malaysia and Iran, respectively, in 2011.

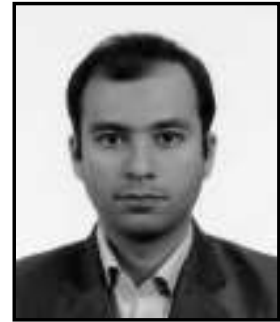

Ali Roshanzamir, He is currently Research Assistant at Institute of Advanced Science and Technology, Research and Training Center, IRAN SSP. He is research assistant of team (8 researchers) to design a Micro-electronic Based nonlinear controller for first order delay system since March, 2015, research student (45 researchers) to Nonlinear control of Industrial Robot Manipulator for Experimental Research and Education from June 2010 to June 


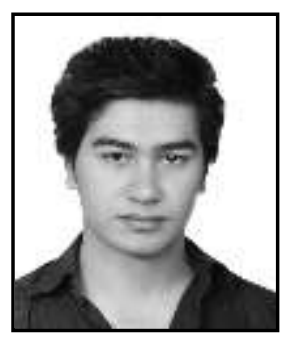

2011, and published 5 journal papers since 2011 to date. His current research interests are nonlinear control, artificial control system, Microelectronic Device, and HDL design.

Arman Jahed, He is currently Research Assistant at Institute of Advanced Science and Technology, Research and Training Center, IRAN SSP. He is research assistant of team (8 researchers) to design a Micro-electronic Based nonlinear controller for first order delay system since March, 2015, research student (45 researchers) to Nonlinear control of Industrial Robot Manipulator for Experimental Research and Education from February 2012 to February 2013, and published 5 journal papers since 2012 to date. His current research interests are nonlinear control, artificial control system, Microelectronic Device, and HDL design.

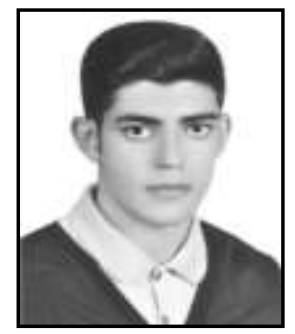

Saman Namvarchi, He is currently Research Student at Institute of Advanced Science and Technology, Research and Training Center, IRAN SSP. He is research student of team (8 researchers) to design a Micro-electronic Based nonlinear controller for first order delay system since March, 2015. His current research interests are nonlinear control, artificial control system, Microelectronic Device, and HDL design.

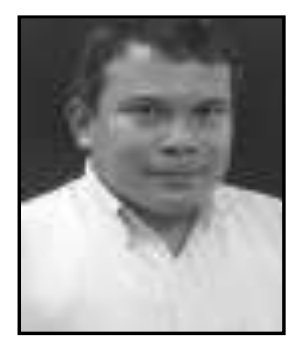

Nasri Sulaiman, $\mathrm{He}$ is a Senior Lecturer in the Department Electrical and Electronic Engineering at the Universiti Purta Malaysia (UPM), which is one of the leading research universities in Malaysia. $\mathrm{He}$ is a supervisor and senior researcher at research and training center called, Iranian Institute of Advanced Science and technology (Iranssp) since 2012. He obtained his M.Sc. from the University of Southampton (UK), and Ph.D. in Microelectronics from the University of Edinburgh (UK). He has published more than 80 technical papers related to control and system engineering, including several co-authored papers with Mr. Piltan. He has been invited to present his research at numerous national and international conferences. He has supervised many graduate students at doctoral and masters level. He is an outstanding scientist in the field of MicroElectronics.

Dr. Nasri Sulaiman advisor and supervisor of several high impact projects involving more than 150 researchers from countries around the world including Iran, Malaysia, Finland, Italy, Germany, South Korea, Australia, and the United States. Dr. Nasri Sulaiman has authored or co-authored more than 80 papers in academic journals, conference papers and book chapters. His papers have been cited at least 3000 times by independent and dependent researchers from around the world including Iran, Algeria, Pakistan, India, China, Malaysia, Egypt, Columbia, Canada, United Kingdom, Turkey, Taiwan, Japan, South Korea, Italy, France, Thailand, Brazil and more.

Dr. Nasri Sulaiman has employed his remarkable expertise in these areas to make outstanding contributions as detailed below:

Design of a reconfigurable Fast Fourier Transform (FFT) Processor using multi-objective Genetic Algorithms (2008-UPM) 
Power consumption investigation in reconfigurable Fast Fourier Transform (FFT) processor (2010-UPM)

Crest factor reduction And digital predistortion Implementation in Orthogonal frequency Division multiplexing (ofdm) systems (2011UPM)

High Performance Hardware Implementation of a Multi-Objective Genetic Algorithm, (RUGS), Grant amount RM42,000.00, September (2012-UPM)

Nonlinear control for industrial robot manipulator (2010-IRAN SSP)

Intelligent Tuning The Rate Of Fuel Ratio In Internal Combustion Engine (2011-IRANSSP)

Design High Precision and Fast Dynamic Controller For MultiDegrees Of Freedom Actuator (2013-IRANSSP)

Research on Full Digital Control for Nonlinear Systems (2011IRANSSP)

Micro-Electronic Based Intelligent Nonlinear Controller (2015IRANSSP)

Active Robot Controller for Dental Automation (2015-IRANSSP)

Design a Micro-Electronic Based Nonlinear Controller for First Order Delay System (2015-IRANSSP) 
International Journal of u- and e- Service, Science and Technology

Vol. 10, No. 1 (2017) 